\title{
The effectiveness of progressive muscle relaxation and high intensity training on depression and quality of life in college students with polycystic ovarian syndrome
}

\author{
Radhika P. K. ${ }^{1 *}$, Tejal Rajandekar ${ }^{2}$, B. Soundarya ${ }^{2}$
}

\begin{abstract}
${ }^{1}$ Department of Physiotherapy, Columbia college of Physiotherapy, Affiliated to Rajiv Gandhi University of Health Sciences, Bangalore, Karnataka, India

${ }^{2}$ Department of Physiotherapy, Narayana Hrudayalaya Institute of Physiotherapy, Affiliated to Rajiv Gandhi University of Health Sciences, Narayana Health city Bangalore, Karnataka, India
\end{abstract}

Received: 10 August 2021

Revised: 13 September 2021

Accepted: 14 September 2021

\section{*Correspondence:}

Dr. Radhika P. K.,

E-mail: radhikapk19922gmail.com

Copyright: (c) the author(s), publisher and licensee Medip Academy. This is an open-access article distributed under the terms of the Creative Commons Attribution Non-Commercial License, which permits unrestricted non-commercial use, distribution, and reproduction in any medium, provided the original work is properly cited.

\section{ABSTRACT}

Background: Polycystic ovarian syndrome (PCOS) is a common hyper androgenic endocrine disorder affecting women of fertile age. This appears to have affects over the psychological aspects and health related quality of life of college students over a period of time. Leading to negative body imaging concern which causes loss of concentration in studies and interest in college activities.

Methods: This was an experimental prospective study carried out with subjects diagnosed with PCOS aged 18-30 years. Self-administered PCOSQ and BDI questionnaire were used to evaluate the health related quality of life and depression. After the data collected from the questionnaire subjects received PMR and HIT for a duration of 6 days a week for 12 weeks' convenient sampling main outcome variables were depression and quality of life. Self-menstrual tracking chart was also given to the students to monitor their menstrual cycle.

Results: The prevalence of depression found in sample was $26 \%$ moderate, $19 \%$ borderline, $52 \%$ mild and $3 \%$ severe depression respectively. Age group in which commonly seen [18-20 years $(n=14), 21-25$ years $(n=15)]$. Patients also showed a negative impact of PCOS on health related QOL (PCOSQ) scale. After PMR and HIT data showed a statistically significant difference $(p<0.05)$ between the pre-test and post-test scores of BDI.

Conclusions: This study provides positive PMR and HIT is an effective therapy for improving the depression related to PCOS and thereby improving the quality of life of college students with PCOS.

Keywords: Beck depression inventory, Depression, High intensity training, Polycystic ovarian syndrome questionnaire, Progressive muscle relaxation, Quality of life

\section{INTRODUCTION}

Polycystic ovarian syndrome (PCOS) is believed to be a heterogeneous, multisystem endocrinopathy mostly affecting women in reproductive age. The term polycystic ovaries suggest that the ovaries that contain multiple miniature cysts usually around ( $<8 \mathrm{~mm}$ diameter), that are situated just beneath the surface of the ovaries. ${ }^{1}$ India has witnessed about $30 \%$ rise in PCOS cases in the last couple of years. Lack of knowledge and lifestyle changes are considered to be the major factor leading to this phenomenon. $^{2}$

PCOS women experiences higher rates of depression which affect their quality of life. Therefore, International as well as Indian guidelines suggest that psychological factors must be considered in all women with PCOS and they must be screened for depression. Yet, a literature 
search revealed only few published Indian studies on this subject. Although there is an evidence of depression in them. International research has shown that PCOS has an adverse effect on the patient's quality of life. The Indian perspective on the QOL in PCOS is untouched. It is very important to understand the symptoms from patients' point of view to gain information on which symptoms cause the maximum impact. So, the therapy can be targeted towards improving the overall outcome of a condition. ${ }^{3}$

Several surveys have confirmed that PCOS is clearly associated with psychological disorders such as depression, anxiety, and binge eating disorder, and healthrelated quality of life. ${ }^{4}$

Depression is more prevalent in women with PCOS and higher scores on self-reported depression symptoms have been observed in women with PCOS. ${ }^{5,6}$

This study intended to find out the effectiveness of PMR and HIT on depression and QOL in college students suffering from PCOS.

\section{Objective}

To find out of the severity of depression in PCOS students. Impact of PMR and HIT technique on depression in PCOS students. Effect PCOS has on health related quality of life (PCOSQ).

\section{METHODS}

The study was conducted online on virtual platform. It was an experimental prospective study in which thirty students were recruited according to the inclusion and exclusion criteria. Study duration was 6 months April 2020 to September 2020.

\section{Inclusion criteria}

Women between age 18-30 years, PCOS diagnosis according to the Rotterdam criteria as confirmed by a gynaecologist, endocrinologist or general practitioner, who scored 11 or higher than that on the BDI, able to read English, willing to participate. Women with no psychiatric illness. Women suffering from other endocrine disorders such as thyroid dysfunction, Cushing's disease, hyper prolactinaemia or diabetes.

\section{Exclusion criteria}

Antidepressants, psychotherapy for depression, on-going pregnancy, and uncontrolled hypertension.

Outcome measures were depression and quality of life.

The content of the program was developed and made after recent studies and research and under the guidance of gynaecology department. Ethical approval was taken from institutional ethical committee and also in accordance with the guidelines of Helsinki declaration, revised 2013. Voluntary written informed consent was obtained from all the participating subjects.

All subjects who fulfilled the inclusion criteria were included in the study by convenient sampling method, questionnaires evaluated the depression and QOL and based on the results of questionnaires patient received the exercise program consisting of PMR and HIT technique.

The purpose and the nature of the study were explained to all the participants.

Statistical analysis was done using the SPSS. The paired ttest was used for comparison of pre and post intervention for BDI. Data for PCOSQ was collected. Demographic data was presented in the tabular form.

The overview treatment session consist of the following:

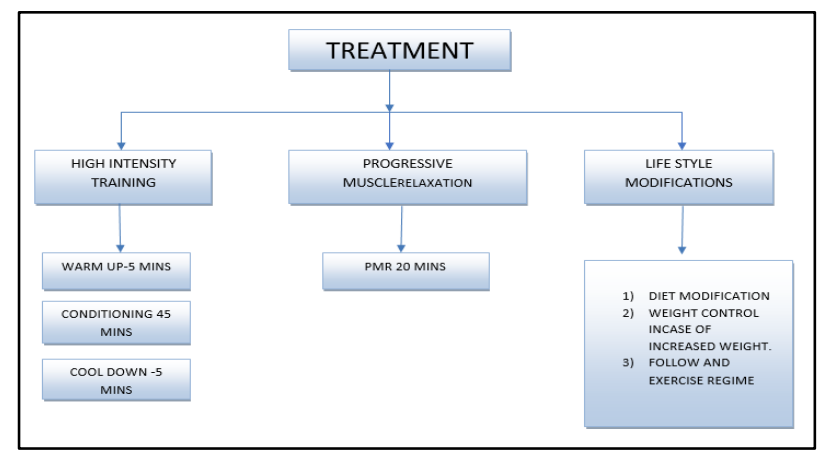

Figure 1: Overview of treatment session.

\section{RESULTS}

Data was analysed and the results were recorded after 12 weeks of physiotherapy intervention. The demographic data of the sample is shown in Table 1 where the mean age of the sample was $21.09 \pm 2.34$ years. Age group were categorized as 18-20 years, 21-25 years, 26-30 years. Figure 2 shows the severity of depression in PCOS participants there are $52 \%$ with mild depression, $26 \%$ with moderate depression, $19 \%$ with borderline depression and $3 \%$ with severe depression.

Mean and standard deviations were calculated for depression pre and post test scores statistics showed significant improvement after the intervention from $17.43 \pm 5.65$ to $11.5 \pm 5.43$ ( $\mathrm{p}$ value $<0.05$ ).

The participants were improved to the normal category $(n=15),(n=10)$ improved and categorized as mild mood disturbance, $(n=4)$ improved and categorized as borderline clinical depression, and $(n=1)$ participants were categorized as moderate depression and zero participants in severe category (Figure 3 ). PCOS have a negative impact on the scale of PCOSQ where we found that the psychological aspect (emotion- 30\%) and the physical 
appearance (body hair- $26 \%$ and weight- $16 \%$ ) were the main concerning domains followed by menstrual problem $(15 \%)$ and infertility (13\%) (Figure 4).

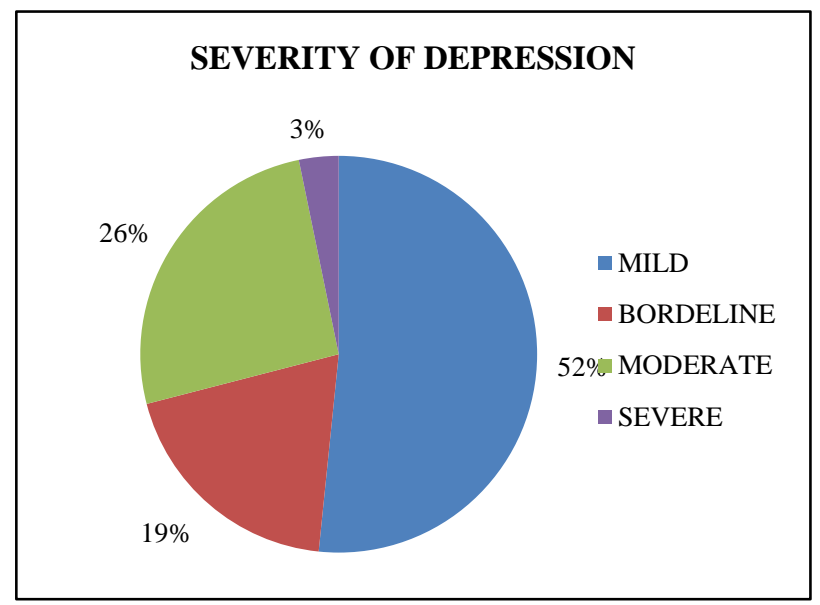

Figure 2: Severity of depression in PCOS participants.

Table 1: Frequency table (demographic data).

\begin{tabular}{|lll|}
\hline Value (age) & Frequency & $\%$ \\
\hline $\mathbf{1 8}$ & 5 & 16.67 \\
\hline $\mathbf{1 9}$ & 5 & 16.67 \\
\hline $\mathbf{2 0}$ & 4 & 13.33 \\
\hline $\mathbf{2 1}$ & 2 & 6.67 \\
\hline $\mathbf{2 2}$ & 5 & 16.67 \\
\hline $\mathbf{2 3}$ & 5 & 16.67 \\
\hline $\mathbf{2 4}$ & 1 & 3.33 \\
\hline $\mathbf{2 5}$ & 2 & 6.67 \\
\hline $\mathbf{2 6}$ & 1 & 3.33 \\
\hline \hline
\end{tabular}

Description statistics- size ( $\mathrm{n}=30)$, median- 21, mid range22, quartiles: $\mathrm{Q}_{1}>19, \mathrm{Q}_{2}>21, \mathrm{Q}_{3}>23$

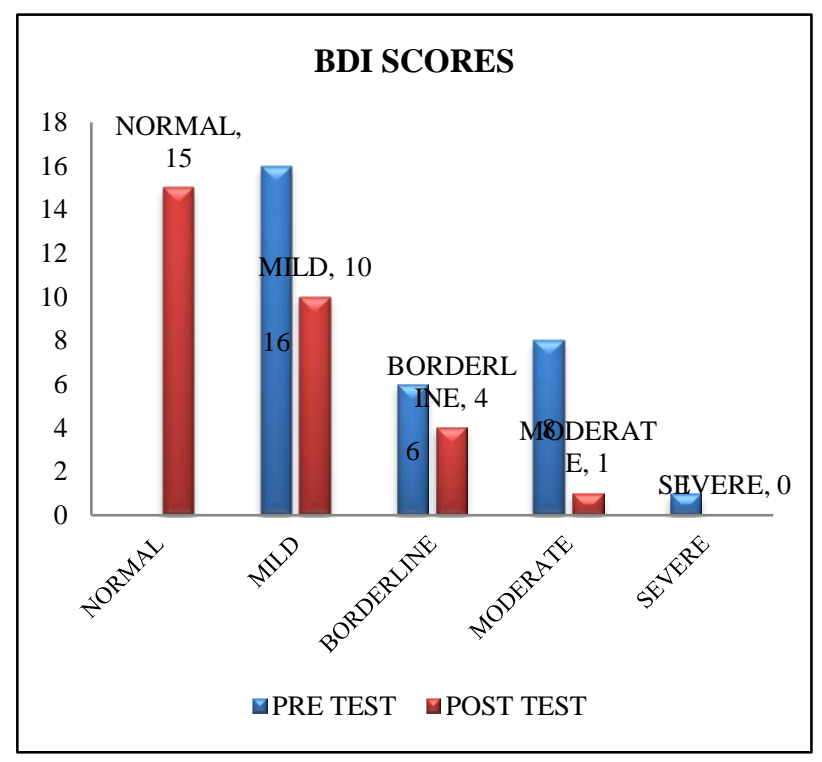

Figure 3: Improvement in the pre- test and post-test values of BDI score after the intervention.
Table 2: Mean and standard deviation calculated for depression in PCOS college students before and after the intervention.

\begin{tabular}{|lll|}
\hline Statistics & $\begin{array}{l}\text { Pre- } \\
\text { intervention }\end{array}$ & $\begin{array}{l}\text { Post- } \\
\text { intervention }\end{array}$ \\
\hline Mean & 17.43 & 11.5 \\
\hline Standard deviation & 5.65 & 5.43 \\
\hline
\end{tabular}

$\mathrm{P}$ value significant at $<0.05$

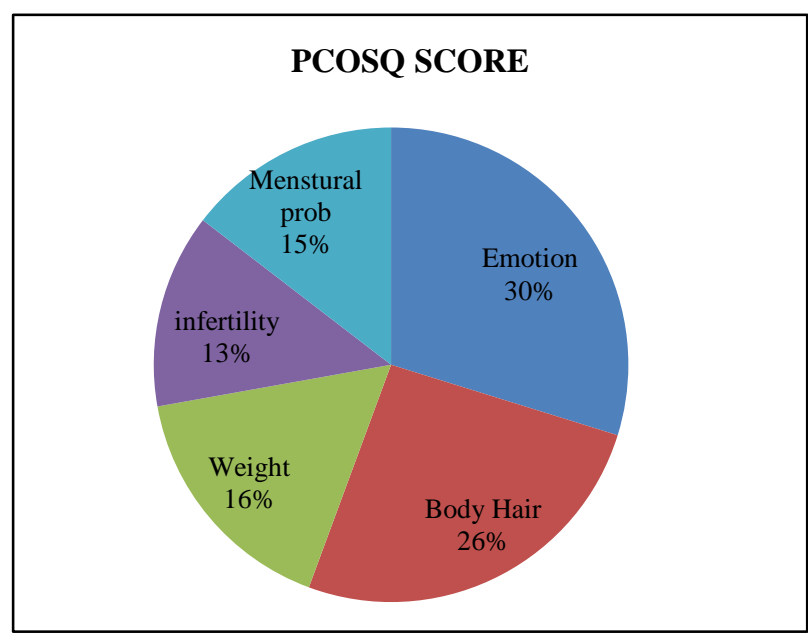

Figure 4: The percentage of impact PCOS has on quality of life of college students.

\section{DISCUSSION}

This study was conducted to analyse the effect of progressive muscle relaxation and high intensity training on depression and quality in college students with polycystic ovarian syndrome. The present study showed these depressive symptoms and also all the domains of PCOSQ are affected in PCOS. Which shows close association with psychological distress which has important implications in the diagnosis and treatment of disorders.

At the baseline, assessment of emotional parameters using Beck depression inventory (BDI) showed that of $(n=16)$ participants were affected by mild mood disturbance, $(n=6)$ were affected by borderline clinical depression, $(n=8)$ were affected by moderate depression and $(n=1)$ were affected by severe depression. After 12 weeks of intervention using these PMR and HIT. Along with this data and interpretation as shown in results (Figure 3) that there is a significant improvement in the severity of clinical Depression.

A study conducted by Jyoti et al on effect of PMR on depression in PCOS supports the claims by our study suggesting that PMR is significantly effective in reducing depression in PCOS patients. ${ }^{7}$ A study conducted by Wang et al about effects of exercise intervention in women with PCOS concludes that exercises is one of the important interventions in PCOS patients and multidisciplinary 
cooperation involving diet, exercise and psychosocial intervention is of great significance in the recent era. For obese PCOS patients dietary and exercises intervention could help improve spontaneous ovulation and induce natural pregnancy. ${ }^{8}$

The PCOSQ domains showed emotion $30 \%$, body hair $26 \%$, weight $16 \%$, infertility $13 \%$ and menstrual domain was $15 \%$ affected. The scores shows negative impact PCOS can have upon the quality of life.

Study findings suggest an increased risk of depression of a significant magnitude in the young PCOS population emphasizing the importance of screening and appropriate follow up in the population. In addition to the gynaecological, endocrine and metabolic features of PCOS, a number of psychological correlates have been identified. Quality of life and psychological well-being are reduced in women with PCOS., 9,10

Therefore, the assessment of HRQL could add vital information to the evaluation of treatment effectiveness in PCOS. For example depression reduces motivation yet good motivation is the key to compliance with medication, exercise, relaxation and dietary management.

PMR is a primary method that can be easily learned to achieve relaxation. It is an effective intervention in reducing emotional distress; PMR is a physical stimulation and mental peace with emphasis on muscle systematic stretching and release (contraction-release). When PMR is practiced regularly, it produces feelings of relaxation throughout the body, which helps to reduce anxiety over time thus reduce depression which frequently co-occurs. ${ }^{11}$ Finally, the psychological health of a women with PCOS should be reviewed regularly for overall well-being.

Furthermore, the results of the meta-analysis showed that HIIT reduced the BMI of women with PCOS, supporting evidence that high-intensity exercise causes higher consumption of oxygen and greater post-exercise energy balance, leading to favourable results in the individuals' body composition. For women with PCOS, the reduction in body mass can help control some consequences of PCOS, such as improvement in menstrual and reproductive function, in addition to influencing psychosocial aspects. $^{12}$

The limitation of the study as follows. The study population was taken from college refusal of participants to participate in the study was the main finding we found which is because they weren't comfortable to discuss in person also about their problem we came to know after speaking to them. This also is a reason for small sample size. More awareness and personal counselling with the students might improve the sample size. Study being conducted on virtual platform lack of appropriate assessment of habitual physical activity.

\section{CONCLUSION}

Hence, it is vital that screening for psychiatric morbidity be incorporated as an ongoing process rather than a onetime assessment. With this study we can conclude that progressive muscle relaxation technique and High intensity training when performed together for a regular period of 12 weeks help in reducing the PCOS related depression and improves the quality of life.

\section{Recommendations}

Study can be done with larger group. More awareness has to be created to improve the participation.

\section{ACKNOWLEDGMENTS}

We would like to thank the Obstetrics and gynaecology department and the physiotherapy department for their support and encouragement. Last but not the least without whom the study wouldn't have taken place, participants.

Funding: No funding sources

Conflict of interest: None declared

Ethical approval: The study was approved by the Institutional Ethics Committee

\section{REFERENCES}

1. Norman RJ, Dewailly D, Legro RS, Hickey TE. Polycystic ovary syndrome. Lancet. 2007;370(9588):685-97.

2. Chadha C, Kataria J, Chugh P, Choudhary A. Quality of life in young adult females with PCOS. Indian J Physiother Occup Ther. 2019;1:40-2.

3. Chaudhari AP, Mazumdar K, Mehta PD. Anxiety, depression, and quality of life in women with polycystic ovarian syndrome. Indian J Psychol Med. 2018;40(3):239-46.

4. Tan J, Wang QY, Feng GM, Li XY, Huang W. Increased risk of psychiatric disorders in women with polycystic ovary syndrome in Southwest China. Chinese Med J. 2017;130(3):262-6.

5. Hollinrake E, Abreu A, Maifeld M, Van Voorhis BJ, Dokras A. Increased risk of depressive disorders in women with polycystic ovary syndrome. Fertil Steril. 2007;87:1369-76.

6. Kerchner A, Lester W, Stuart SP, Dokras A. Risk of depression and other mental health disorders in women with polycystic ovary syndrome: a longitudinal study. Fertil Steril. 2009;91:207-12.

7. Parle J, Savant AD. The effect of progressive muscle relaxation on depression in polycystic ovarian syndrome. Int J Reprod Contracept Obstet Gynecol. 2018;7:3029-33.

8. Wang S, Zhang Z, Liu Y. Effects of Exercise Intervention on the Improvement of Polycystic Ovary Syndrome. In: Wang Z, ed. Polycystic Ovarian Syndrome. Intech Open. 2019. 
9. Elsenbruch S, Benson S, Hahn S, Tan S, Mann K, Pleger K, et al. Determinants of emotional distress in women with polycystic ovary syndrome. Hum Reprod. 2006;21:1092-9.

10. Barnard L, Ferriday D, Guenther N, Strauss B, Balen AH, Dye L, et al. Quality of life and psychological well-being in polycystic ovary syndrome. Hum Reprod. 2007;22:2279-86.

11. Li Y, Wang R, Tang J, Chen C, Tan L, Wu Z, et al. Progressive muscle relaxation improves anxiety and depression of pulmonary arterial hypertension patients. Evidence-Based Complement Altern Med. $2015 ; 2015$.
12. Blackshaw LCD, Chhour I, Stepto NK, Lim SS. Barriers and facilitators to the implementation of evidence-based lifestyle management in polycystic ovary syndrome: a narrative review. Med Sci. 2019;7:76.

Cite this article as: Radhika PK, Rajandekar T, Soundarya B. The effectiveness of progressive muscle relaxation and high intensity training on depression and quality of life in college students with polycystic ovarian syndrome. Int J Reprod Contracept Obstet Gynecol 2021;10:3880-4. 